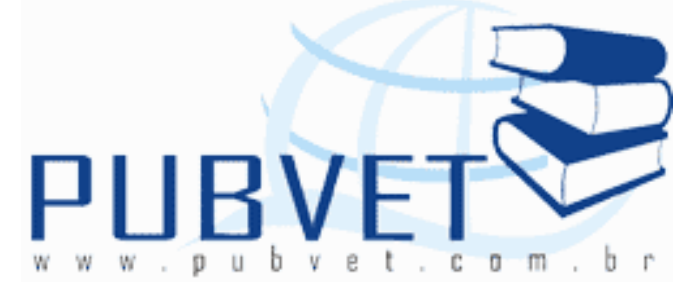

PUBVET, Publicações em Medicina Veterinária e Zootecnia.

\title{
Avaliação de enzimas hepáticas de ovelhas que receberam sais minerais diferenciados durante três períodos reprodutivos
}

\author{
Vanessa Veronese Ortunho ${ }^{1}$, Wilmar Sachetin Marçal ${ }^{2}$, Mara Regina Stipp \\ Balarin $^{2}$, Nelson Parizotto Junior ${ }^{3}$
}

${ }^{1}$ Aluna de pós graduação Stricto sensu da Universidade Estadual de Londrina, Paraná, Brasil, e-mail: vanessaverort@yahoo.com.br

2 Docente da Universidade Estadual de Londrina, Departamento de Clínica Veterinária-CCA

${ }^{3}$ Aluno de pós-graduação Stricto sensu da Universidade Estadual de Londrina.

\section{Resumo}

Com os objetivos de detectar se a utilização de diferentes formulações minerais poderia alterar os valores das enzimas hepáticas: AST (Aspartato Transaminase), FA (Fosfatase Alcalina) e GGT (Gama-glutamil transferase), introduzir na literatura valores destes parâmetros de fêmeas criadas no Paraná e comparar as alterações sanguíneas que ocorrem durante o período seco, gestação e 10 dias do pós-parto, realizou-se este trabalho. Foram utilizadas 30 fêmeas ovinas da raça Suffolk, as quais foram separadas aleatoriamente em dois grupos de 15 fêmeas: um grupo recebeu sal mineral comercial contendo componentes inorgânicos e o outro grupo recebeu sal mineral comercial contendo alguns minerais orgânicos na forma de carboaminofosfoquelato. 0 sistema adotado foi o confinamento e o sal mineral foi fornecido ad libitum. As 
colheitas de sangue foram mensais e iniciaram um mês antes do início da estação de monta, que iniciou quando as fêmeas estavam com aproximadamente 8 meses de idade. A suplementação mineral somente interferiu nos valores de FA. A presença da gestação não influenciou nenhum parâmetro analisado.

Palavras-chave: Enzimas hepáticas. Suplementação mineral. Ovelhas.

\title{
Enzymes hepatics of sheep that was received different minerals in $\mathbf{3}$ periods
}

\begin{abstract}
The objectives of this study were to compare the effects of supplementation with organic and inorganic minerals in hepatic enzymes, to compare the changes that occurs in 3 reproductives periods and provide to literature values of this parameter in the females created in Paraná State, was made this experiment. The objects of the study were 30 Suffolk ewes randomly distributed in two groups of 15 females. A control group received inorganic commercial mineral salt and the challenge group received commercial mineral salt containing some organic minerals in the carboaminofosfoquelate form. The adopted system was the confinement and the salt was supplied ad libitum. All animals had blood collected monthly and the first collect was one month before the breeding season started, when the females were approximately 8 months old. There was difference in the alkaline phosphatase analyzed when it was compared to the two commercial formulations, although the pregnant animals did not show difference in parameters analyzed.
\end{abstract}

Keywords: Hepatic enzymes. Mineral supplementation. Sheep.

\section{Introdução}

A ovinocultura segundo, Brito et al.,(2006), tem avançado no Brasil nos últimos anos, e por consequência muitas patologias vem ocorrendo 
com maior frequência, principalmente as de origem metabólica, como a Toxemia da Prenhez, que podem ser evitadas ou minimizadas com a adoção de práticas simples, tanto no manejo nutricional, com a introdução de uma dieta adequada e balanceada, quanto no sanitário do rebanho com o controle de patologias que provoquem anorexia ou diminuição do apetite das fêmeas (SILVA; SILVA, 1983); (ORTOLANI, 2009).

Uma ferramenta importante que pode ser usada para auxiliar os clínicos no diagnóstico das doenças metabólicas é o uso do perfil metabólico, pois ele avalia vários sistemas, detecta lesões teciduais e transtornos no funcionamento de órgãos, através de análises sanguíneas, no leite, na urina e na saliva (GONZÁLEZ; SCHEFFER, 2003); (RICCÓ, 2004).

Ortolani (2009) sugere que na análise do perfil metabólico a determinação da atividade da enzima GGT seja realizada, pois indicará a função hepática. Caso haja tendência de ocorrer Toxemia da Prenhez, devido o acúmulo de gordura no fígado, sua função estará prejudicada, aumentando os teores do parâmetro em questão, que nesta patologia, poderá estar acima de 30 UI/L. Também é recomendada a análise da atividade da FA durante a gestação, pois nos casos severos de Toxemia da Prenhez ela pode estar aumentada, embora seja pouco específica para distúrbios hepáticos em ovinos (PASTOR, LOSTE, SÁEZ, 2001).

A importância dos exames sanguíneos como meio semiológico, auxiliando os veterinários a estabelecerem diagnósticos, firmarem prognósticos e acompanharem os tratamentos das inúmeras enfermidades que atingem os animais domésticos é reconhecida e consagrada mundialmente. Entretanto, para que esses objetivos possam ser alcançados e utilizados na plenitude, tornou-se fundamental o conhecimento dos valores de referência do perfil metabólico dos animais sadios, assim como de suas variações (VIANA et al, 2002). 
Segundo, Eshratkhah et al., (2011) e Braun; Trumel; Bézille, (2010), alguns estudos internacionais estão sendo realizados porém, na maioria deles não estão bem especificados os detalhes dos animais; como raça, manejo e idade; os métodos estatísticos usados para determinar os limites de referência são questionáveis, trazendo um prejuízo na comparação e observação clínica dos resultados obtidos por outros autores. Eles ainda recomendam que devido a estes fatores, os valores de referência podem ser produzidos e validados por cada laboratório, pois cada um utiliza uma metodologia diferente e geralmente analisa sangue de animais da região próxima de onde situa o laboratório, facilitando assim, a interpretação dos resultados.

No Brasil os resultados ainda são escassos, dificultando à clínica e um maior entendimento sobre os animais criados no país, então de forma notória, há necessidade da realização de pesquisas que estudem os animais criados no país e os fatores de variação sobre os valores sanguíneos. Entre esses fatores merece destaque aqueles relacionados à alimentação, gestação, à parição e ao puerpério.

Pela nutrição ser um dos itens que mais oneram a produção; recentemente, uma tecnologia tem despertado interesse nos pesquisadores, na indústria e nos produtores que é o uso dos minerais orgânicos nas misturas ofertadas para os animais (PEIXOTO et al., 2005). Eles são formados por um mineral ligado a uma molécula orgânica, como aminoácidos ou carboidratos, e quando processados recebem o nome de quelatos, formando estruturas com características próprias, como alta biodisponibilidade, tamanho pequeno e ausência de cargas elétricas (SPEARS, 1996); (KELLOGG, KEGLEY, 2002) e (PAL et al., 2010).

Como, na ovinocultura poucos estudos com esse tipo de mineral vem sendo desenvolvidos Spears, (1996) relata que pesquisas com esta suplementação devem ser realizadas, visando: definir o nível de inclusão destes minerais nas dietas; estudar o custo-benefício da adoção desta 
tecnologia, determinar o modo de ação dos quelatos nos ruminantes e estabelecer o comportamento destes minerais em relação às diferentes espécies de animais

A existência de poucas informações na literatura brasileira relativa aos valores plasmáticos de AST, GGT e FA dos ovinos e, principalmente, a ausência, no Brasil, de pesquisas que avaliem a influência de fatores indutores de variação nos parâmetros sanguíneos estimulou a elaboração da presente pesquisa que teve como objetivos verificar a influência da suplementação orgânica nos valores sanguíneos das enzimas citadas, comparar as alterações sanguíneas que ocorrem durante o período seco, gestação e 10 dias do pós-parto e introduzir na literatura valores sanguíneos de fêmeas sadias criadas no Paraná.

\section{Material e Métodos}

O experimento foi realizado numa propriedade rural localizada no município de Prado Ferreira, $23^{\circ} 02^{\prime} 22^{\prime \prime}$ de latitude Sul, $51^{\circ} 26^{\prime} 32^{\prime \prime}$ de longitude Oeste e $651 \mathrm{~m}$ de altitude, norte do Paraná, Brasil (IPARDES, 2007).

Foram utilizadas 30 fêmeas ovinas da raça Suffolk, as quais foram separadas aleatoriamente em dois grupos de 15 fêmeas: um grupo recebeu sal mineral comercial inorgânico e o outro grupo recebeu sal mineral comercial contendo alguns minerais orgânicos, na forma de carboaminofosfoquelato. Para que não houvesse mistura entre os lotes, foi colocado colar nos animais, sendo que cada grupo, usou uma cor. Optou-se por trabalhar com sal mineral comercial para que pudesse ser simulado o que realmente ocorre no campo.

As fêmeas iniciaram o consumo dos sais aos 4 meses de idade, ao desmame, com pesos iniciais de $20,26 \pm 4,54 \mathrm{~kg}$ para as fêmeas que receberam sal mineral orgânico e 21,9 $\pm 4,9 \mathrm{~kg}$ para as fêmeas que receberam 
ORTUNHO, V.V. et al. Avaliação de enzimas hepáticas de ovelhas que receberam sais minerais diferenciados durante três períodos reprodutivos. PUBVET, Londrina, V. 7, N. 2, Ed. 225, Art. 1493, 2013.

sal mineral inorgânico. O sistema adotado foi o confinamento e a alimentação consistiu de ração comercial (23,04\% Proteína Bruta), cujo consumo era de 2 kg/animal por dia; cana picada, que era oferecida todos os dias; água e sal mineral; fornecidos à vontade nos cochos.

As composições dos sais minerais para ovinos utilizados encontram-se detalhadas na Tabela 1, a seguir.

Tabela 1 - Fórmula do sal mineral orgânico e inorgânico que foi fornecido ao grupo experimental e controle, em níveis de garantia por $\mathrm{kg}$ do produto.

\begin{tabular}{ccc}
\hline Elemento & $\begin{array}{c}\text { Formulação Mineral } \\
\text { Orgânica }\end{array}$ & $\begin{array}{c}\text { Formulação Mineral } \\
\text { Inorgânica }\end{array}$ \\
\hline Cálcio & $120 \mathrm{~g}$ & $140 \mathrm{~g}$ \\
Fósforo & $87 \mathrm{~g}$ & $60 \mathrm{~g}$ \\
Sódio & $147 \mathrm{~g}$ & $136 \mathrm{~g}$ \\
Enxofre & $* 18 \mathrm{~g}$ & $5 \mathrm{~g}$ \\
Cobre & $* 590 \mathrm{mg}$ & $150 \mathrm{mg}$ \\
Cobalto & $* 40 \mathrm{mg}$ & $90 \mathrm{mg}$ \\
Cromo & $* 20 \mathrm{mg}$ & - \\
Ferro & $* 1.800 \mathrm{mg}$ & - \\
Iodo & $80 \mathrm{mg}$ & $180 \mathrm{mg}$ \\
Manganês & $* 1.300 \mathrm{mg}$ & $400 \mathrm{mg}$ \\
Selênio & $* 15 \mathrm{mg}$ & $13 \mathrm{mg}$ \\
Zinco & $* 3.800 \mathrm{mg}$ & $3.000 \mathrm{mg}$ \\
Molibdênio & $300 \mathrm{mg}$ & - \\
Flúor (máx.) & $870 \mathrm{mg}$ & $600 \mathrm{mg}$ \\
Magnésio & - & $6 \mathrm{~g}$ \\
Cloro & - & $216 \mathrm{~g}$ \\
Lisina & - & $200 \mathrm{mg}$ \\
Metionina (máx.) & - & $40 \mathrm{mg}$ \\
Tirosina & - & $82 \mathrm{mg}$ \\
Solubilidade do & $95 \%$ & $95 \%$ \\
Fósforo em Acido & & \\
Cítrico a 2\% & & \\
(mín) & & \\
& ${ }^{*}$ minerais orgânicos & \\
\hline
\end{tabular}

Em março de 2008 quando os animais estavam com aproximadamente 8 meses; 35,33 $\pm 4,46 \mathrm{~kg}$ grupo orgânico e 37,2 $\pm 6,45 \mathrm{~kg}$ grupo inorgânico, foram colocados em estação de monta, a qual teve duração de 3 meses, e para que não houvesse interferência do macho, houve rodízio 
ORTUNHO, V.V. et al. Avaliação de enzimas hepáticas de ovelhas que receberam sais minerais diferenciados durante três períodos reprodutivos. PUBVET, Londrina, V. 7, N. 2, Ed. 225, Art. 1493, 2013.

mensal na cobertura. Após 2 meses de seu término, foi realizado o exame de ultrasonografia para verificação da quantidade de ovelhas prenhes no rebanho, as quais não foram separadas do lote inicial para que não fosse introduzida outra variável.

A primeira colheita de sangue foi realizada 1 mês antes das ovelhas entrarem em estação de monta, fevereiro de 2008. A segunda colheita foi realizada no dia que a estação de monta foi iniciada e as outras colheitas foram realizadas conforme o estado reprodutivo da fêmea, tabela 2 e 3.

Após o parto e com os dados da ultrasonografia, calculou-se em que mês as ovelhas ficaram prenhes, então, para elas adotou-se o calendário de colheita que está explicado na tabela 2.

Tabela 2 - Calendário de colheita de sangue das fêmeas que emprenharam durante o experimento.

\begin{tabular}{cc}
\hline Colheitas & Realizada \\
\hline 1 & 1 mês antes do início da estação de monta (fev. 2008) \\
2 & dia do início da estação de monta (março 2008) \\
3 & 10 mês de gestação \\
4 & 20 mês de gestação \\
5 & 30 mês de gestação \\
6 & 40 mês de gestação \\
7 & 50 mês de gestação \\
8 & 10 dias do pós-parto \\
\hline
\end{tabular}

Para as fêmeas que não emprenharam o calendário de colheita de sangue está descrito na tabela 3 .

Tabela 3 - Calendário de colheita de sangue das fêmeas que não emprenharam durante o experimento.

\begin{tabular}{cc}
\hline Colheitas & Realizada \\
\hline 1 & 1 mês antes do início da estação de monta (fev. 2008) \\
2 & dia do início da estação de monta (março 2008) \\
3 & abril 2008 \\
4 & maio 2008 \\
5 & junho 2008 \\
6 & julho 2008 \\
7 & agosto 2008 \\
8 & setembro 2008 \\
\hline
\end{tabular}


As colheitas de sangue foram realizadas após jejum over-night e através de venopunção da jugular utilizando o sistema a vácuo com agulhas BD Vacutainer $\AA$ descartáveis $22 \mathrm{G} \mathrm{X} \mathrm{1",} \mathrm{adaptador} \mathrm{para} \mathrm{tubos} \mathrm{de} \mathrm{colheita} \mathrm{e}$ tubos de $10 \mathrm{ml}$ sem anticoagulante. $\mathrm{O}$ transporte dos tubos até o laboratório foi realizado em estantes verticais, sendo que o conjunto estante- tubos foi colocado numa inclinação de aproximadamente $45^{\circ}$ para facilitar a separação do soro.

As amostras foram centrifugadas por 10 minutos para obtenção do soro, o qual foi colocado em tubos de eppendorf e congelados para posteriores análises. A concentração do AST, GGT e FA foi obtida por espectrofotometria utilizando metodologia cinética colorimétrica do kit comercial da Gold Analisa. As amostras foram analisadas no Laboratório de Patologia Clínica do Hospital Veterinário da Universidade Estadual de Londrina.

Os dados obtidos foram avaliados através do programa SAEG (UFV, 2007). Foram realizadas análises de variância, testes de Tukey, regressão linear e múltipla dos parâmetros sanguíneos, tendo-se calculado as interações entre tipo de sal ofertado com presença de prenhes (TXP), tipo de sal ofertado com dias de colheita (TxD) e presença de prenhes com dias de colheita (PXD). Optou-se por fazer estudo da regressão até $3^{\circ}$ grau, para facilitar o estudo e a comparação entre os dados encontrados na literatura. Também se calculou no mesmo programa, pelo teste Qui-Quadrado, os dados de taxa de prenhez.

\section{Resultados e Discussão}

A literatura consultada avalia a influência da ingestão de um mineral na dieta, não estudando a influência de duas composições minerais comerciais compostas por aminoácidos, elementos minerais orgânicos e inorgânicos. Este estudo, então, simulou o que ocorre nos parâmetros 
sanguíneos das ovelhas em vários períodos produtivos e reprodutivos das propriedades rurais do Brasil, que utilizam estas formulações.

Durante a estação de monta, obteve-se 6 fêmeas prenhes no grupo que recebeu suplementação mineral inorgânica e 2 no grupo que recebeu suplementação com minerais orgânicos, segundo o teste QuiQuadrado, não houve diferença estatística na taxa de prenhez. Acredita-se que esta taxa pode ter sido influenciada pelo consumo da cana, que é pobre em vitamina $A$, pelo baixo peso das fêmeas no início da estação de monta e por serem nulíparas.

Para facilitar a análise dos dados, os grupos foram denominados de $T$ para tipo de sal consumindo e $P$ para presença ou não de prenhes, no experimento ficando as seguintes combinações:

-TOPO fêmeas que receberam sal inorgânico e que não ficaram prenhes,

-TOP1 fêmeas que receberam sal inorgânico e que emprenharam,

-T1P0 fêmeas que receberam sal orgânico e que não ficaram prenhes e

-T1P1 fêmeas que receberam sal orgânico e que emprenharam.

Os resultados obtidos estão apresentados na Tabela 4.

Observa-se, segundo a tabela 4, que o tipo de sal ofertado durante o experimento somente interferiu nos valores de FA $(P \leq 0,01)$; tendo as ovelhas que receberam formulação mineral orgânica maiores valores desta enzima. Esta pesquisa concorda com Mohri et al., (2011) quando pesquisaram cordeiros Baloochi que estavam divididos em 2 grupos, sendo que um deles recebeu vitamina $E$ e selenito de sódio injetados na dose de $0,2 \mathrm{mg} / \mathrm{kg}$ e o outro grupo recebeu a mesma dose de solução salina, os autores encontraram menores valores na enzima AST no grupo que recebeu o mineral inorgânico.

Esta pesquisa, porém discorda de Hatfield et al., (2002) quando suplementam 4 grupos de ovelhas Targhee secas com diferentes doses de zinco orgânico e os autores não encontraram diferenças nas atividades de FA. 
ORTUNHO, V.V. et al. Avaliação de enzimas hepáticas de ovelhas que receberam sais minerais diferenciados durante três períodos reprodutivos. PUBVET, Londrina, V. 7, N. 2, Ed. 225, Art. 1493, 2013.

Verifica-se, também que a presença ou ausência de prenhes não mostrou efeito significativo nos valores dos parâmetros analisados, não concordando com El-Sherif e Assad (2001) e Batavani; Ghasemzadeh; Kheradmand (2008) que encontraram maiores valores de AST durante a gestação e explicam que nesta fase a enzima pode agir com um catalisador no metabolismo de aminoácidos e carboidratos e sabidamente na gestação a demanda destas substâncias aumenta os autores também afirmam que um aumento da enzima pode ocorrer devido ao início da funcionalidade dos órgãos do feto.

Tabela 4 - Médias observadas de AST, FA, GGT em função do tipo de sal, presença ou não de prenhes e dias de colheita.

\begin{tabular}{|c|c|c|c|}
\hline Fontes de variação & AST (UI/I) & FA (UI/I) & GGT (UI/I) \\
\hline \multicolumn{4}{|l|}{ Tipo de sal (T) } \\
\hline Sal inorgânico (0) & 167,96 & $153,94 b$ & 34,50 \\
\hline Sal orgânico (1) & 172,30 & 173,36 a & 34,98 \\
\hline \multicolumn{4}{|l|}{ Prenhes (P) } \\
\hline Ausente (0) & 165,89 & 161,33 & 34,44 \\
\hline Presente (1) & 174,37 & 165,97 & 35,04 \\
\hline \multicolumn{4}{|l|}{ Colheita } \\
\hline 1 & 120,20 & 169,50 & 35,11 \\
\hline 2 & 188,27 & 181,03 & 32,15 \\
\hline 3 & 174,86 & 161,33 & 35,88 \\
\hline 4 & 157,87 & 136,13 & 38,98 \\
\hline 5 & 166,52 & 185,13 & 36,25 \\
\hline 6 & 199,84 & 168,53 & 33,05 \\
\hline 7 & 190,50 & 170,36 & 32,15 \\
\hline 8 & 181,14 & 190,57 & 34,21 \\
\hline Médias Gerais & 170,13 & 163,65 & 34,75 \\
\hline \multicolumn{4}{|l|}{ Significância F } \\
\hline Tiро & NS & $* *$ & NS \\
\hline Prenhes & NS & NS & NS \\
\hline Interação TXP & $* *$ & $*$ & NS \\
\hline Interação TXD & NS & NS & NS \\
\hline Interação PxD & NS & NS & NS \\
\hline $\begin{array}{l}\text { Coeficiente de } \\
\text { variação }\end{array}$ & 16,213 & 39,14 & 20,25 \\
\hline
\end{tabular}


Observa-se que mesmo tendo a influência do sal mineral nos valores de $\mathrm{FA}$, todos os valores encontrados nesta pesquisa estão dentro do intervalo de referência para a espécie, Kaneko, (1997). Concordando com Davis et al. (2006), que pesquisaram a influência do selênio inorgânico em ovelhas Rambouillett de 4 anos de idade e os valores encontrados de FA, AST e GGT estavam dentro da normalidade.

Para os valores plasmáticos obtidos de AST e FA, pode-se observar na tabela 4 que as interações calculadas de tipo de sal com dias de colheita e presença de prenhes com dias de colheita não apresentaram diferença estatística. Por outro lado, a interação do tipo de sal ofertado com a presença ou não de prenhes foi significativa os dados observados encontramse na tabela 5 e 6.

Tabela 5 - Médias de AST plasmática (UI/I) de acordo com o tipo de sal e a presença ou ausência de prenhez.

\begin{tabular}{l|ll|l}
\hline & Sal Inorgânico & Sal Orgânico & Médias \\
\hline Não Prenhes & 171,32 A a & 160,47 B b & 165,89 \\
Prenhes & 164,61 B a & 184,13 A a & 174,37 \\
\hline Médias Gerais & 167,96 & 172,30 & \\
\hline
\end{tabular} $\begin{aligned} & \text { Médias seguidas de letras diferentes maiúscula na horizontal e } \\
& \text { minúsculas na vertical diferem entre si significativamente pelo } \\
& \text { Teste de Tukey a 5\%. }\end{aligned}$

Observa-se pela tabela 5 que o tipo de sal ofertado durante 0 experimento influenciou $(P<0,05)$ os valores de AST nas fêmeas não prenhes durante o experimento. Sendo que as fêmeas que receberam sal mineral inorgânico tiveram maior média no parâmetro analisado, quando se compara com as fêmeas no mesmo estado reprodutivo, porém que receberam sal orgânico. 
O tipo de sal ofertado também influenciou, $(P<0,05)$, as fêmeas prenhes durante o experimento possuindo maior valor de AST as que receberam sal orgânico.

Não houve diferença quando se analisa somente as fêmeas que receberam sal inorgânico, ou seja, as fêmeas prenhes e as que estavam secas durante o experimento, têm média de AST plasmática semelhante estatisticamente. Porém, quando se analisa os animais que receberam sal orgânico, as fêmeas prenhes apresentaram maiores valores de AST $(P<0,05)$.

Tabela 6- Médias de FA plasmática, (UI/I), de acordo com o tipo de sal e a presença ou ausência de prenhes.

\begin{tabular}{|c|c|c|c|}
\hline & Sal Inorgânico & Sal Orgânico & Médias \\
\hline Não Prenhes & $165,30 \mathrm{~A} \mathrm{a}$ & $157,37 \mathrm{~A} \mathrm{~b}$ & 161,33 \\
\hline Prenhes & $142,58 \mathrm{~B} \mathrm{a}$ & $189,36 \mathrm{~A} \mathrm{~b}$ & 165,97 \\
\hline Médias Gerais & 153,94 & 173,36 & \\
\hline
\end{tabular}

Observa-se pela tabela 4 que o tipo de sal ofertado durante 0 experimento não influenciou $(P<0,05)$ os valores de $F A$ nas fêmeas não prenhes durante o experimento. Porém, as fêmeas prenhes que receberam sal mineral orgânico tiveram maior média neste parâmetro, quando se compara com as fêmeas no mesmo estado reprodutivo, que receberam sal inorgânico.

Não houve diferença quando se analisa somente as fêmeas que receberam sal inorgânico, ou seja, as fêmeas prenhes e as que estavam secas durante 0 experimento, têm média de FA plasmática semelhante estatisticamente. Da mesma forma acontece, quando se analisa os animais que receberam sal inorgânico. 
ORTUNHO, V.V. et al. Avaliação de enzimas hepáticas de ovelhas que receberam sais minerais diferenciados durante três períodos reprodutivos. PUBVET, Londrina, V. 7, N. 2, Ed. 225, Art. 1493, 2013.

\section{Conclusões}

Este estudo simulou o que ocorre nos parâmetros sanguíneos das ovelhas em vários períodos produtivos e reprodutivos das propriedades rurais do Brasil, que utilizam as formulações minerais utilizadas no experimento.

Esta pesquisa mostrou a necessidade da realização de estudos com minerais orgânicos que avaliem a concentração plasmática de FA, AST e GGT de ovelhas secas, gestantes e lactantes, para que se possa estabelecer o custo-benefício da adoção desta tecnologia, determinar o modo de ação dos quelatos nos ovinos, estabelecer o comportamento destes minerais em relação às diferentes espécies de animais e investigar a relação deste mineral nas características de carcaça e nos metabólitos sanguíneos.

Este trabalho mostrou a necessidade da realização de pesquisas que avaliem os animais criados no país para que a realização do monitoramento dos animais seja facilitada, portanto os resultados encontrados enriquecem o meio científico e poderão ser utilizados em outros estudos, como comparação.

Pode-se concluir com este experimento que as formulações minerais ofertadas para as fêmeas estudadas influenciaram somente os valores plasmáticos de FA.

Não houve influência dos períodos reprodutivos na avaliação da FA, GGT e AST.

\section{Referências}

BATAVANI; GHASEMZADEH; KHERADMAND, Changes of enzyme activities in ovine fetal fluids and maternal blood serum with gestational age. Comp. Clin. Pathol, London, v. 17, p. 105$109,2008$.

BRITO, A.M., et al. Composição do sangue e do leite em ovinos leiteiros do sul do Brasil: variações na gestação e na lactação. Ciência Rural, Santa Maria, v.36, n.3, p.942-948, maijun, 2006.

DAVIS, P. A. et al. Tolerance of inorganic selenium by range-type ewes during gestation and lactation. Journal of Animal Science, Florida. v. 84, p. 660-668, 2006. 
ORTUNHO, V.V. et al. Avaliação de enzimas hepáticas de ovelhas que receberam sais minerais diferenciados durante três períodos reprodutivos. PUBVET, Londrina, V. 7, N. 2, Ed. 225, Art. 1493, 2013.

EL-SHERIF, M.M.A.; ASSAD, F. Change in some blood constituints of Barki ewes during pregnancy and lactation under semi arid conditions. Small Ruminant Research 40, p.269277,2001

ESHRATKHAH, B. et al. Relationship between the level of plasma insulin and lipidprofile in Iranian fat-tailed sheep. Comparative Clinical Pathology, Iran, v.20, n.3, p.223-226, 2011.

GONZÁLEZ, F.H.D., SCHEFFER, J.F.S. (2003) Perfil sanguíneo: ferramenta de análise clínica, metabólica e nutricional. In: González, FH.D., Campos, R. (eds.): Anais do I Simpósio de Patologia Clínica Veterinária da Região Sul do Brasil. Porto Alegre: Gráfica da Universidade Federal do Rio Grande do Sul. p.73-89.

HATFIELD, P.G. et al. Serum $a$-tocopherol and immune function in yearling ewes supplemented with zinc and vitamin E. Journal of Animal Science, Montana. v. 80, p.1329-1334, 2002

INSTITUTO PARANAENSE DE DESENVOLVIMENTO ECONOMICO E SOCIAL - IPARDES. Área, altitude e coordenadas geográficas, segundo os municípios do Paraná. In: Anuário estatístico do Estado do Paraná. Curitiba, 2007. Disponível em:

<http://www.ipardes.gov.br/anuario_2007/1territorio/tab1_1_1.htm> Acesso em: 20 out. 2008.

KANEKO, J. J. Carbohidrate Metabolism and its disease. In: domestic animals. 5. ed. New York: Academic Press, 1997. p. 45-81. Clinical biochemistry of

KELLOGG; D.W., KEGLEY, E.B. Organic-Chelated Minerals. Feed supplements, p. 981-996, V[ ], 2002.

ORTOLANI, E. L. Monografia. Toxemia da prenhez em pequenos ruminantes: como reconhecê-la e evita-la. Acesso site: 25/08/2009

http://br.monografias.com/trabalhos901/toxemia-prenhez-ruminantes/toxemia-prenhezruminantes.shtml

PAL, D. T. et al. Effect of copper- and zinc-methionine supplementation on bioavailability, mineral status and tissue concentrations of copper and zinc in ewes. Journal of Trace Elements in Medicine and Biology, India, v. 24, p. 89-94, 2010.

PASTOR, J.; LOSTE, A.; SÁEZ, T. La toxemia de gestación en la Oveja. Pequeños Ruminantes, [s.I.], v. 2, n. 3,18-24, 2001.

PEIXOTO, P.V., et al. Princípios de suplementação mineral em ruminantes. Pesquisa Veterinária Brasileira, Brasil. v.25, ed.3, p.195-200, 2005.

RICCÓ, D. Indicadores sanguíneos e corporais de avaliação metabólico-nutricional em ruminantes. 2004. 13f. Seminário (Pós-Graduação em Ciências Veterinárias) - Universidade Federal do Rio Grande do Sul, Porto Alegre. Disponível em:

<http://www6.ufrgs.br/bioquimica/posgrad/BTA/perfil_ruminantes.pdf> Acesso em: 30 abr. 2008.

SAEG . Sistema para Análises Estatísticas, Versão 9.1: Fundação Arthur Bernardes - UFV Viçosa, 2007.

SILVA, A. E. D. F.; SILVA, M. U. D. CONCEITOS DE HIGIENE NO MANEJO PERINATAL DA CRIAÇÃO CAPRINA. SOBRAL: EMBRAPA - CNPC, 1983. 
ORTUNHO, V.V. et al. Avaliação de enzimas hepáticas de ovelhas que receberam sais minerais diferenciados durante três períodos reprodutivos. PUBVET, Londrina, V. 7, N. 2, Ed. 225, Art. 1493, 2013.

SPEARS, J. W. Organic trace minerals in ruminant nutrition. Animal Feed Science and Technology, Amsterdam, v. 58, n. 1/2, p. 151-163, 1996.

VIANA, R.B. et al. Influência da gestação e do puerpério sobre o leucograma de caprinos da raça Saanen, criados no Estado de São Paulo. Brazilian Journal Veterinarian Research Animal Science, São Paulo. v. 39, n.4, p. 196-201, 2002. 